\title{
Pituitary function after transsphenoidal surgery including measurement of basal morning cortisol as predictor of adrenal insufficiency
}

\author{
Ida Staby ${ }^{1}$, Jesper Krogh ${ }^{1}$, Marianne Klose ${ }^{1}$, Jonas Baekdal' ${ }^{1}$, Ulla Feldt-Rasmussen ${ }^{1,2}$, Lars Poulsgaard ${ }^{3}$, \\ Jacob Bertram Springborg ${ }^{3}$ and Mikkel Andreassen ${ }^{1,2}$ \\ 'Department of Medical Endocrinology and Metabolism, Rigshospitalet, Copenhagen University Hospital, Copenhagen, Denmark \\ ${ }^{2}$ Department of Clinical Medicine, Faculty of Health and Clinical Sciences, Copenhagen University, Copenhagen, Denmark \\ ${ }^{3}$ Department of Neurosurgery, Rigshospitalet, Copenhagen University Hospital, Copenhagen, Denmark
}

Correspondence should be addressed to M Andreassen: mikkel.andreassen.01@regionh.dk

\begin{abstract}
Introduction: Patients with pituitary adenomas undergoing transsphenoidal surgery require pre- and post-surgery examination of pituitary hormones. There is currently no consensus on how to evaluate the adrenal axis post-surgery. The aims of this study were to investigate factors that may predict postoperative adrenal insufficiency (Al) and to investigate the overall effect of transsphenoidal surgery on pituitary function. Methods: One hundred and forty-three consecutive patients who had undergone transsphenoidal surgery for pituitary adenomas were included. Data on tumour size, pituitary function pre-surgery, plasma basal cortisol measured within $48 \mathrm{~h}$ post-surgery and pituitary function 6 months post-surgery were collected. Patients with Al prior to surgery, perioperative glucocorticoid treatment, Cushing's disease and no re-evaluation after 1 month were excluded $(n=93)$ in the basal cortisol analysis.

Results: Low plasma basal cortisol post-surgery, tumour size and previous pituitary surgery were predictors of $\mathrm{Al}$ (all $P<0.05$ ). A basal cortisol cut-off concentration of $300 \mathrm{nmol} / \mathrm{L}$ predicted Al 6 months post-surgery with sensitivity and negative predictive value of $100 \%$, specificity of $81 \%$ and positive predictive value of $25 \%$. New gonadal, thyroid and adrenal axis insufficiencies accounted for 2, 10 and 10\%, respectively. The corresponding recovery rates were 17,7 and $24 \%$, respectively Conclusion: Transsphenoidal surgery had an overall beneficial effect on pituitary endocrine function. Low basal plasma cortisol measured within $48 \mathrm{~h}$ after surgery, tumour size and previous surgery were identified as risk factors for Al. Measurement of basal cortisol postsurgery may help to identify patients at risk of developing Al.
\end{abstract}
Key Words
- basal cortisol
- adrenal insufficiency
- pituitary surgery
- pituitary endocrine function
- transsphenoidal surgery
- central hypothyroidism
- hypogonadotropic hypogonadism

\section{Introduction}

Pituitary adenomas are found in almost all cases of benign tumours with an incidence of around 3-4 per 100,000 and account for approximately $15 \%$ of all primary brain tumours (1). They are categorized into functioning and non-functioning adenomas depending on hormone secretion. Pituitary adenomas may cause symptoms due to mass effects for example, compression of the optic chiasm and visual field defects, as well as

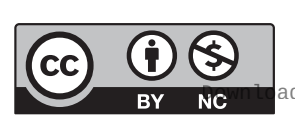

This work is licensed under a Creative Commons Attribution-NonCommercial 4.0 International License. ded from Bioscientifica.com at 04/26/2023 02:00:27PM
Endocrine Connections (2021) 10, 750-757 
compromizing pituitary function leading to various degrees of hypopituitarism (2). Prolactinomas are traditionally treated medically, while non-functioning pituitary adenomas (NFPAs), corticotropin-producing tumours and growth hormone-producing tumours are usually treated surgically $(3,4)$. Indications for surgery are in most of the cases ofhormone hypersecretion and/or visual field defects. The risk of tumour-related hypopituitarism seems associated with tumour size, and some studies have shown beneficial effects of pituitary surgery $(5,6,7,8)$; however, hypopituitarism is generally not considered an indication for pituitary surgery (9). Evaluation of pituitary function is crucial as part of proper management. All patients should be clinically and biochemically examined for hormone hypersecretion pre-surgery and hypopituitarism both before and after surgery. Evaluation of hypopituitarism includes clinical examination and assessment of pituitary hormone axes. Most crucial is the evaluation of adrenal function to secure proper treatment of adrenal insufficiency (AI) and to avoid an adrenal crisis. There are different ways to examine the adrenal axis pre-surgery, for example, the measurement of random spot plasma cortisol, measurement of cortisol after adrenocorticotropic hormone (ACTH) stimulation (Synacthen -test) or measurement of cortisol during hypoglycaemia (insulin tolerance test (ITT) (4). By contrast, it is a challenge to evaluate the adrenal axis after pituitary surgery since the Synacthen-test is unreliable in the first weeks of postsurgery $(3,4,10)$ and it is not without risk to perform ITT in the perioperative phase. Thus, several approaches have been suggested, ranging from routine use of prophylactic glucocorticoid treatment to glucocorticoid sparing regimens with close observation and only treatment in case of clinical signs of AI $(3,4,11)$. Some studies have investigated that if the measurement of cortisol in the postoperative days might predict long-term AI (12, $13,14,15,16,17,18)$, but it is still controversial how to manage the hypothalamus-pituitary-adrenal axis postoperatively.

The primary aim of this study was to investigate factors that may predict postoperative AI including early postoperative basal plasma cortisol concentrations. The secondary aim was to investigate the overall effect of transsphenoidal surgery on the pituitary endocrine function by comparing the numbers of insufficient axis before and after transsphenoidal surgery in a cohort of consecutive patients treated within the last 2 years.

\section{Patients and methods}

\section{Patients}

Consecutive patients undergoing transsphenoidal surgery for functioning and NFPAs between 1 January 2018 and 30 July 2020 were included in the study. All patients had surgery at the Department of Neurosurgery, Rigshospitalet, Copenhagen University Hospital, Denmark. The department of Neurosurgery receives patients from Eastern Denmark with 2.7 million inhabitants, corresponding to roughly half of the Danish population. All patients were operated by one of three pituitary surgeons of the department using neuronavigation-guided microscopic endonasal technique. The septal mucosa was incised at the level of the sphenoid rostrum, and the mucosacovered septum was lateralized, thereby sparing the nasoseptal artery.

Pre- and post-surgery hormonal assessment was mainly done at the Department of Biochemistry at Rigshospitalet. From patient's files, we collected data on age, gender, type and size of tumour, medical history, medication, previous pituitary surgery and radiation therapy, pituitary function pre- and post-surgery (pituitary hormone levels (thyroidstimulating hormone (TSH), luteinizing hormone (LH), follicle-stimulating hormone (FSH), growth hormone (GH) and prolactin) and end-organs hormone levels (results of Synacthen ${ }^{\circledast}$ tests, morning cortisol, free thyroxin (T4), testosterone and oestradiol) and outcome of examinations including imaging and pathology reports. Complete data of all pituitary axes were not available. A patient was included in the analyses only if at least one axis evaluation was available during both pre- and post-surgery.

\section{Ethics}

The study was approved by the executive committee at Rigshospitalet on 11 May 2020. Due to the retrospective design, informed consent was not obtained/required.

\section{Preoperative evaluation}

Patients were classified as adrenal insufficient if they had random spot plasma cortisol $<100 \mathrm{nmol} / \mathrm{L}$, and plasma cortisol $<420 \mathrm{nmol} / \mathrm{L} 30 \mathrm{~min}$ after ACTH stimulation or were treated with hydrocortisone. In case if the plasma cortisol after Synacthen ${ }^{\oplus}$-test was very close to the cut-off level, the test was repeated before the final diagnosis was made. Central hypothyroidism was defined as plasma 
free $\mathrm{T} 4$ concentrations in the low normal range or below the lower normal concentration and inappropriately low plasma TSH; hypogonadotropic hypogonadism as reduced plasma total testosterone with inappropriately low concentrations of LH for men, and low oestradiol with inappropriately low levels of LH or FSH for women together with amenorrhoea/oligomenorrhoea for premenopausal women. A diagnosis of Cushing's disease or acromegaly was established according to the standard criteria. We did not report on GH deficiency or anti-diuretic hormone insufficiency because only a few patients were examined with GH stimulation test or reported clinical signs of diabetes insipidus pre-surgery. The widest tumour diameter in any plane recorded by the MRI rapport preoperatively was collected. If no rapport was available, the patients were excluded from the analysis of tumour size.

\section{Perioperative evaluation}

To evaluate the risk of AI (excluding patients with Cushing's disease), a measurement of basal plasma cortisol on 1st or 2nd postoperative day at 06:00 $\mathrm{h}$ was obtained. If patients had both 1st- and 2nd-day cortisol concentrations measured, the 2nd-day measurement was included in the analysis (15). Patients who had normal adrenal function pre-surgery started hydrocortisone treatment if basal cortisol post-surgery was $<300 \mathrm{nmol} / \mathrm{L}$. Patients who were diagnosed with AI pre-surgery or received glucocorticoids in the perioperative phase were excluded from the evaluation of the predictive role of basal plasma cortisol.

\section{Postoperative evaluation}

We aimed to include test results of 6 months post-surgery or as close to 6 months as possible. For the assessment of adrenal function by Synacthen -test $(250 \mu \mathrm{g})$, a minimum of 4 weeks between surgery and post-surgical Synacthen test was required (10). Patients on hydrocortisone therapy paused hydrocortisone for at least $16 \mathrm{~h}$ before the Synacthen-test was performed. Criteria for post-surgery deficits of the anterior pituitary axes were similar to the pre-surgical definitions.

\section{Biochemical analyses}

Pituitary and end-organ hormones were measured by validated commercially available assays. Cortisol was measured by the Elecsys cort 2 assay (CORTII) from Roche. Most cortisol measurements in patients and controls were done using the same method and laboratory facilities.
Normal range for plasma cortisol $30 \mathrm{~min}$ post ACTH stimulation was based on 100 healthy control subjects (10). The 2.5-percentile concentration for plasma cortisol 30 min after ACTH stimulation measured by the CORTII assay was $420 \mathrm{nmol} / \mathrm{L}(19)$.

\section{Statistics}

Statistical analyses and data collection were performed in IBM SPSS statistics version 26 .

Results are presented as mean ( \pm 1 S.D.) for normally distributed variables and as median (IQR) for nonnormally distributed variables. Assumption of normal distribution was assessed by histograms. Continuous variables were compared by independent sample $t$-test, whereas categorical data were compared by $\chi^{2}$-test and Fisher's exact test. Age, gender, tumour size and basal cortisol as predictors of AI 6 months post-surgery were investigated by binary logistic regression. Basal cortisol as predictor of AI was also assessed by Fisher's exact test with dichotomization of plasma cortisol with a cut-off of $300 \mathrm{nmol} / \mathrm{L}$. Furthermore, the sensitivity, specificity, positive predictive value (PPV) and negative predictive value (NPV) of different basal cortisol levels were calculated. The relationship between tumour size and insufficient pituitary axes pre-surgery was evaluated by binary logistic regression. $P$ value $<0.05$ was considered statistically significant.

\section{Results}

\section{Baseline}

One hundred and forty-three patients with pituitary adenomas (NFPAs, GH-producing tumours, prolactinomas and ACTH-producing tumours) were included in the study (Fig. 1 and Table 1). Fifty-one percent were men, and the mean age was $57 \pm 16$ years. The median tumour size was $28 \mathrm{~mm}$ (17-33). Men had larger tumours compared with women, $28(23-36)$ vs $23 \mathrm{~mm}(15-31)(P=0.022)$, respectively. Twelve out of 15 patients with Cushing's disease had a microadenoma, whereas $8 / 32$ of acromegalic patients had a microadenoma (two had unknown size). One hundred and twenty patients had transsphenoidal pituitary surgery for the first time, 17 for the second time and 6 for the third time surgery. None of the patients had received radiation therapy prior to surgery. No women received oral contraceptives containing oestrogens or oestradiol substitution when the adrenal function was

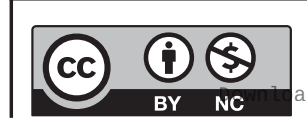

This work is licensed under a Creative Commons Attribution-NonCommercial 4.0 International License. ded from Bioscientifica.com at 04/26/2023 02:00:27PM 


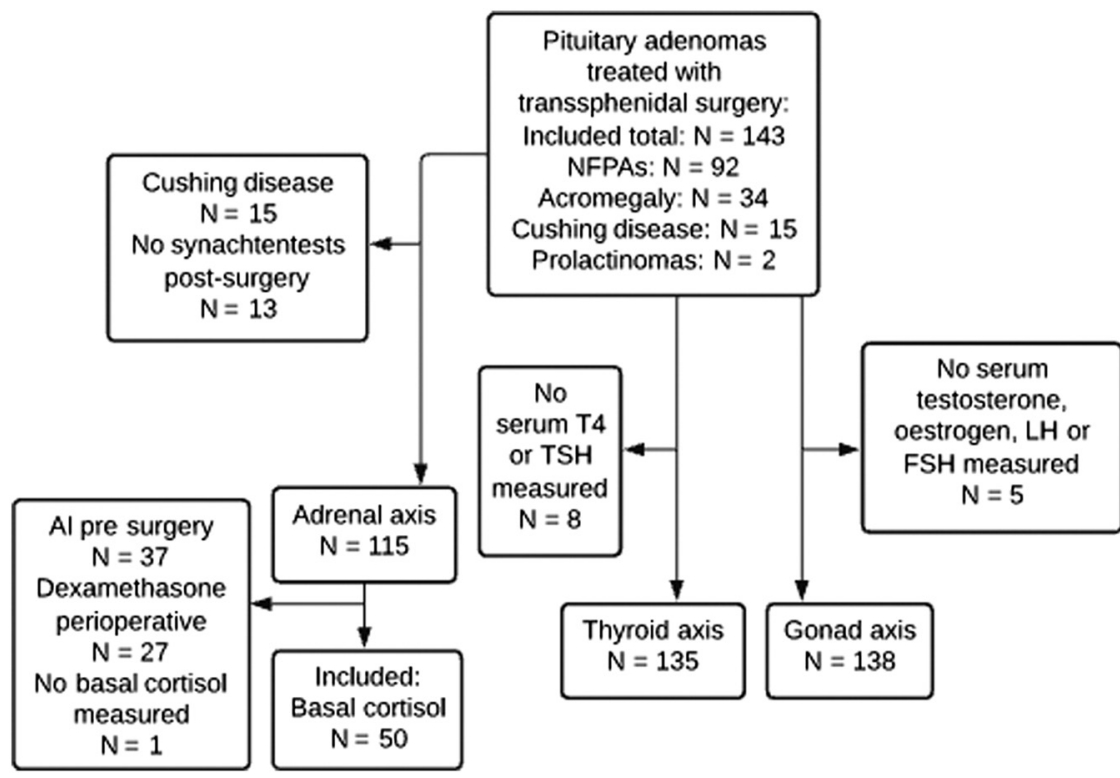

\begin{abstract}
Figure 1
Summary of patients evaluated both pre- and post-surgery for each of the three investigated axes (adrenal axis, thyroid axis and gonad axis). Al, adrenal insufficiency; NFPAs, non-functioning pituitary adenomas; TSH, thyroid-stimulating hormone; LH, luteinizing hormone; FSH, follicle-stimulating hormone; T4, thyroxine.
\end{abstract}

evaluated. Indication for surgery in all patients with NFPA was visual field defects. Two patients with prolactinomas had surgery due to dopamine agonist-resistant tumours.

\section{Pre-surgery hormonal assessment}

Hypogonadotropic hypogonadism prior to surgery was the most common insufficiency in 95/138 (68\%), followed by central hypothyroidism 75/135 (55\%) and secondary AI 41/128 (32\%) (Table 2). A diagnosis of AI pre-surgery was based on an insufficient Synacthen test $(n=31)$, random spot cortisol below $100 \mathrm{nmol} / \mathrm{L}$ $(n=5)$ or hydrocortisone therapy $(n=5)$. The remaining patients had a sufficient adrenal axis assed by a sufficient Synacthen -test $(n=61)$, random spot cortisol above 420 nmol/L $(n=4)$ or no evidence of AI based on symptoms, plasma sodium concentrations and blood pressure $(n=22)$. Hypothyroidism was observed more often in patients who had previous surgery $17 / 23$ (74\%) vs no previous surgery $58 / 112(52 \%)(P=0.04)$. For the other two axes, there were no differences between first-time surgery and previous surgery (Table 2).

Numbers of insufficient axes were significantly correlated to tumour size in surgery-naïve patients (Table 3); adrenal axis odds ratio (OR) $1.074(1.024-1.27)(P=0.003)$, thyroid axis OR $1.084(1.038-1.131)(P<0.001)$, gonadal axis OR $1.162(1.096-1.232)(P<0.001)$, all ORs represent the risk of insufficiency per $1 \mathrm{~mm}$ increase in tumour size.

\section{Post-surgery hormonal assessment}

\section{Predictors of adrenal insufficiency post-surgery}

In the analysis of the predictive role of plasma cortisol measured on 1st or 2 nd post-surgical day, we excluded 93 patients due to AI pre-surgery $(n=37)$, missing basal cortisol measurement $(n=1)$, perioperative treatment with dexamethasone as an antiemetic $(n=27)$, Cushing's disease $(n=15)$ or missing evaluation of the adrenal axis post-surgery by Synacthen -test $(n=13)$ (Fig. 1$)$. Thus, 50 patients were included (measurement on the 1st postsurgical day $n=37$, 2 nd day $n=13$ ). Eleven patients had a basal cortisol measurement on both 1st and 2nd postsurgical days.

The median cortisol concentration on 1 st or 2 nd postoperative day was 486 (306-965 (range: 56-1520) $\mathrm{nmol} / \mathrm{L})$. Among the 50 patients evaluated by early basal plasma cortisol, three turned out to have developed AI when evaluated by Synacthen-test approximately

Table 1 Baseline characteristics.

\begin{tabular}{l}
\hline$n$ \\
Age (years, s.D.) \\
Men/women \\
Tumour size, median (IQR), mm \\
First surgery/previous surgery
\end{tabular}

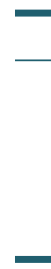

https://ec.bioscientifica.com

https://doi.org/10.1530/EC-21-0155

\begin{tabular}{c}
\hline Total \\
\hline 143 \\
$57(16)$ \\
$73 / 70$ \\
$28(17$ to 33$)$ \\
$120 / 23$
\end{tabular}

(c) 2021 The authors Published by Bioscientifica Ltd

\begin{tabular}{c}
\hline NFPA \\
\hline 92 \\
$61(15)$ \\
$50 / 42$ \\
$30(25$ to 35$)$ \\
$76 / 16$
\end{tabular}

\begin{tabular}{c}
\hline $\mathbf{G H}$ \\
\hline 34 \\
$52(13)$ \\
$18 / 16$ \\
$15(10$ to 23$)$ \\
$33 / 1$ \\
\hline
\end{tabular}

\begin{tabular}{c}
\hline ACTH \\
\hline 15 \\
$43(17)$ \\
$4 / 11$ \\
$9(5$ to 16$)$ \\
$10 / 5$ \\
\hline
\end{tabular}

\begin{tabular}{c}
\hline PRL \\
\hline 2 \\
59 and 18 \\
$1 / 1$ \\
42 and 36 \\
$1 / 1$
\end{tabular}

This work is licensed under a Creative Commons Attribution-NonCommercial 4.0 International License. ded from Bioscientifica.com at 04/26/2023 02:00:27PM 
Table 2 Association between insufficiency and previous surgery vs surgery-naïve.

\begin{tabular}{lc}
\hline & Total insufficiencies \\
Adrenal axis, $n=128 *$ & $41 / 128(32 \%)$ \\
Thyroid axis, $n=135$ & $75 / 135(55 \%)$ \\
Gonadal axis, $n=138$ & $95 / 138(68 \%)$ \\
\hline
\end{tabular}

*patients with Cushing's disease were excluded.

6 months after surgery. The diagnosis was based on 30 min plasma cortisol levels during Synacthen -test of $103 \mathrm{nmol} / \mathrm{L}, 143 \mathrm{nmol} / \mathrm{L}$, and $191 \mathrm{nmol} / \mathrm{L}$, respectively. The three patients who developed AI had a 1st or 2 nd postoperative day cortisol concentration of $<300 \mathrm{nmol} / \mathrm{L}$. The OR for developing AI was $3.4(1.0-12.3)(P=0.056)$ per $100 \mathrm{nmol} / \mathrm{L}$ decrease in basal cortisol. Assessed by Fisher's exact test (cut-off $300 \mathrm{nmol} / \mathrm{L}$ ), patients who developed AI had lower basal cortisol concentrations than patients who sustained an intact adrenal axis $(P=0.01)$. With a cut-off of $300 \mathrm{nmol} / \mathrm{L}$ the sensitivity and NPV was $100 \%$, specificity 81\% and PPV 25\% (Table 4).

Risk of developing AI post-surgery was higher in patients who were previously operated compared to surgery-naïve patients $4 / 9(44 \%)$ vs $4 / 73(5 \%)(P=0.04)$. Tumour size also predicted post-surgery AI, OR 1.09 (1.031.15) $(P=0.005)$ per $1 \mathrm{~mm}$ increase in tumour size. There was no relationship between risk of developing AI and age $(P=0.16)$ or gender $(P=0.11)$.

\section{Overall effects of transshpenoidal surgery}

Overall, a beneficial effect of pituitary surgery on pituitary function (Table 5) evaluated 7.1 \pm 3.1 months post-surgery was found, with endocrine recovery rates exceeding the number of new insufficiencies. Recovery rates for the adrenal, thyroid and gonadal axes were 8/33 (24\%), 5/75 (7\%) and 16/95 (17\%), respectively (Table 5), whereas rates of new insufficiencies were $8 / 82$ (10\%, adrenal axis), $6 / 62$ (10\%, thyroid axis) and $1 / 43$ (2\%, gonadal axis), respectively (Table 5). As for the adrenal axis, tumour size also predicted post-surgery thyroid insufficiency, OR 1.08 (1.03-1.12) $(P<0.001)$ and gonadal insufficiency OR 1.17 (1.10-1.24) $(P<0.001)$, both ORs are per $1 \mathrm{~mm}$ increase in tumour size. In contrast to the adrenal axis, there was no association between the number of surgeries and risk of developing insufficiency of the thyroid $(P=0.48)$ or gonadal axes $(P=1.00)$.

In 78 patients, Synacthen -test was also performed after 1 month and in 75 patients after 3 months. After 1 month, five patients showed discrepant results when comparing results of Synacthen -test 1 month vs 3 months, and after 3 months, four patients showed discrepant results (3 months vs 6 months).

\section{Discussion}

The main result from the present study is that three risk factors for developing permanent AI post-surgery were identified: low plasma basal cortisol measured within 48 $h$ after transsphenoidal surgery, increased tumour size and previous surgery. Furthermore, in the hands of a dedicated pituitary surgeon, transsphenoidal surgery had an overall beneficial effect on pituitary function with more endocrine recoveries than new insufficiencies.

The dilemma when managing potential post-surgery AI is the low risk of AI, against the consequence of missing the diagnosis of AI, which might be fatal in case of an adrenal crisis. The strategy at Rigshospitalet until 1 January 2018 was to perform Synacthen -test and clinical examination 1 week, 1 month and 3 months post-surgery, and only initiate hydrocortisone therapy in case of low concentrations of unstimulated cortisol or an insufficient Synacthen -test (10). Since 2018, the measurement of basal cortisol within $48 \mathrm{~h}$ after surgery has been added to the algorithm, as has the initiation of hydrocortisone treatment if plasma cortisol was $<300 \mathrm{nmol} / \mathrm{L}$. Of 50 patients evaluated by early basal cortisol, only three developed AI during follow-up, and they all had plasma basal cortisol post-surgery below $300 \mathrm{nmol} / \mathrm{L}$. By contrast, the majority of patients who remained with intact adrenal function had high basal

Table 3 Association between tumour size and insufficient axes in surgery-naïve patients.

\begin{tabular}{llc}
\hline Total & & $\mathbf{1 - 1 0} \mathbf{~ m m}$ \\
\cline { 1 - 1 } Adrenal axis, $n=103 *$ & & $1 / 8(13 \%)$ \\
Thyroid axis, $n=104$ & & $3 / 13(23 \%)$ \\
Gonadal axis, $n=107$ & & $4 / 14(29 \%)$
\end{tabular}

\begin{tabular}{l}
\hline $\mathbf{1 1 - 2 0} \mathbf{~ m m}$ \\
\hline $2 / 20(9 \%)$ \\
$5 / 20(25 \%)$ \\
$7 / 20(35 \%)$ \\
\hline
\end{tabular}

\begin{tabular}{c}
\hline $\mathbf{2 1 - 3 0 ~} \mathbf{m m}$ \\
\hline $14 / 39(36 \%)$ \\
$21 / 37(57 \%)$ \\
$29 / 39(74 \%)$ \\
\hline
\end{tabular}

\begin{tabular}{c}
\hline $\mathbf{3 1 - 4 0} \mathbf{~ m m}$ \\
\hline $12 / 31(39 \%)$ \\
$21 / 29(72 \%)$ \\
$28 / 30(95 \%)$ \\
\hline
\end{tabular}

\begin{tabular}{l}
$>\mathbf{4 0} \mathbf{~ m m}$ \\
\hline $4 / 5(80 \%)$ \\
$4 / 5(80 \%)$ \\
$4 / 4(100 \%)$ \\
\hline
\end{tabular}

$\begin{array}{r}\hline \text { P value } \\ \hline 0.003 \\ <0.001 \\ <0.001 \\ \hline\end{array}$

*patients with Cushing's disease were excluded. 
Table 4 Association between basal cortisol and adrenal axis 6 months post-surgery.

\begin{tabular}{l}
\hline $\begin{array}{l}\text { Basal cortisol } \\
\text { concentration }(\mathrm{nmol} / \mathrm{L})\end{array}$ \\
\hline $0-99$ \\
$100-199$ \\
$200-299$ \\
$300-399$ \\
$400-499$ \\
$500-599$ \\
$\geq 600$ \\
Total
\end{tabular}

\begin{tabular}{c}
\hline Sufficient \\
\hline 2 \\
2 \\
5 \\
9 \\
4 \\
4 \\
21 \\
47 \\
\hline
\end{tabular}

\begin{tabular}{c}
\hline Insufficient \\
\hline 2 \\
0 \\
1 \\
0 \\
0 \\
0 \\
0 \\
3
\end{tabular}

\begin{tabular}{ccc}
\hline & & \\
Total & & Cut-off limits $(\mathrm{nmol} / \mathrm{L})$ \\
\cline { 1 - 1 } 4 & & 100 \\
2 & & 200 \\
6 & & 300 \\
9 & & 400 \\
4 & & 500 \\
4 & & 600 \\
21 & \\
50 &
\end{tabular}

\begin{tabular}{ccc}
\cline { 1 - 1 } Specificity $(\%)$ & & Sensitivity (\%) \\
\cline { 1 - 1 } 96 & & 67 \\
92 & & 67 \\
81 & & 100 \\
62 & & 100 \\
53 & & 100 \\
45 & & 100
\end{tabular}

\begin{tabular}{|c|c|}
\hline NPV (\%) & PPV (\%) \\
\hline 98 & 50 \\
\hline 98 & 33 \\
\hline 100 & 25 \\
\hline 100 & 14 \\
\hline 100 & 12 \\
\hline 100 & 10 \\
\hline
\end{tabular}

cortisol levels (21/47 had basal cortisol $>600 \mathrm{nmol} / \mathrm{L})$, probably reflecting post-surgical physiological stress, in agreement with a recently published study measuring basal cortisol post transsphenoidal surgery (15).

According to the study by Prencipe et al. (15), the 2nd-day basal cortisol was a better predictor of AI. The 2nd-day cortisol cut-off concentration suggested in the manuscript was $386 \mathrm{nmol} / \mathrm{L}$ (sensitivity and NPV 100\%, specificity $57 \%$ and PPV $26 \%$ ). With only 11 patients having measured plasma basal cortisol concentration on both 1st and 2nd postoperative days in the present paper, data were insufficient to elucidate if the 2 nd postoperative day was more accurate in predicting AI than the 1st day. Friso de Vries et al. suggested a serum cortisol cut-off of $220 \mathrm{nmol} / \mathrm{L}$ (2nd or 3rd postoperative day, sensitivity 86\%, specificity 92\%, PPV 76\%, NPV 95\%) (18), whereas Jayasena et al. proposed a 5th-day serum cortisol cut-off cortisol of $392 \mathrm{nmol} / \mathrm{L}$ (sensitivity 100\%, specificity 46\%, PPV 76\%) (14). Several other studies have shown that basal cortisol concentrations < $111 \mathrm{nmol} / \mathrm{L}$ were strong predictors of permanent AI $(13,14,16,17)$. In addition to basal cortisol, we identified tumour size as a risk factor for developing AI. Finally, previous pituitary surgery was also a risk factor for developing AI. Only 5\% of surgery-naïve patients developed AI compared to almost $50 \%$ of patients having previous surgery. Gerges et al. (20) also found an increased risk of developing anterior pituitary dysfunction after reoperations $(n=19)$; however, it was not specific for the adrenal axis as seen in the present study. By contrast, Chang et al. did not find a worsening of endocrine function in any patient undergoing repeated transsphenoidal surgery $(n=81)(21)$. In a subgroup, the adrenal function was also evaluated by Synacthen -test on 1 and 3 months post-surgery. Most patients had concordant results when comparing 30 min plasma cortisol with the result after 6 months, but around 5\% showed discrepant results, supporting that Synacthen-test may not be fully reliable in the first weeks/months after surgery.

Taken together, despite the increasing amount of data, there is still controversy concerning how best to manage the adrenal axis after pituitary surgery. Our results, as well as others $(12,13,14,15,16,17,18)$, support that the vast majority of patients developing AI post-surgery can be identified by measuring basal cortisol, although the results from the present study were based on very few cases. In our study, AI was a rare complication to transsphenoidal surgery, which resulted in a relatively low PPV, despite a high specificity. Nine out of 47 patients with normal adrenal function post-surgery may have received unnecessary hydrocortisone initiated by the measurement of low basal cortisol. However, by measuring basal cortisol, the majority of patients with intact adrenal axis may avoid needless

Table 5 Endocrine outcomes of transsphenoidal surgery including the comparison of first surgery vs previous surgery.

\begin{tabular}{|c|c|c|c|c|c|}
\hline \multicolumn{2}{|l|}{ Pre- vs post-surgery } & $\begin{array}{l}\text { Sufficient pre- and } \\
\text { post-surgery }(\%)\end{array}$ & $\begin{array}{c}\text { New } \\
\text { insufficiencies (\%) }\end{array}$ & $\begin{array}{l}\text { Insufficient pre- and } \\
\text { post-surgery }(\%)\end{array}$ & Recoveries (\%) \\
\hline \multirow[t]{3}{*}{ Adrenal axis, $n=115^{*}$} & Total, $n=115$ & $74 / 82(90)$ & $8 / 82(10)$ & $25 / 33(76)$ & $8 / 33(24)$ \\
\hline & First surgery $n=101$ & 69/73 (95) & 4/73 (5) & $20 / 28(71)$ & $8 / 28(29)$ \\
\hline & Previous surgery $n=14$ & $5 / 9(56)$ & $4 / 9(44)$ & $5 / 5(100)$ & $0 / 5(0)$ \\
\hline \multirow[t]{3}{*}{ Thyroid axis, $n=135$} & Total, $n=135$ & $54 / 60(90)$ & $6 / 60(10)$ & $70 / 75(93)$ & $5 / 75(7)$ \\
\hline & First surgery $n=112$ & $49 / 54(91)$ & $5 / 54(9)$ & $53 / 58(91)$ & $5 / 58(9)$ \\
\hline & Previous surgery $n=23$ & $5 / 6(83)$ & $1 / 6(17)$ & $17 / 17(100)$ & $0 / 17(0)$ \\
\hline \multirow[t]{3}{*}{ Gonadal axis, $n=138$} & Total, $n=138$ & $42 / 43(98)$ & $1 / 43(2)$ & $79 / 95$ (83) & $16 / 95$ (17) \\
\hline & First surgery $n=115$ & $38 / 39(97)$ & $1 / 39(3)$ & $61 / 76(80)$ & $15 / 76(20)$ \\
\hline & Previous surgery $n=23$ & $4 / 4(100)$ & $0 / 4(0)$ & $18 / 19(95)$ & $1 / 19(5)$ \\
\hline \multicolumn{2}{|c|}{$\begin{array}{l}\text { https://ec.bioscientifica.com } \\
\text { https://doi.org/10.1530/EC-21-0155 }\end{array}$} & $\begin{array}{l}2021 \text { The authors } \\
\text { y Bioscientifica Ltd }\end{array}$ & & \multicolumn{2}{|c|}{$\begin{array}{l}\text { This work is licensed under a Creative Commons } \\
\text { Attribution-NonCommercial } 4.0 \text { International License }\end{array}$} \\
\hline
\end{tabular}


treatment with glucocorticoids. It should be emphasized that a few weeks of treatment of an intact adrenal axis with glucocorticoids is well known to cause iatrogenic AI (22, 23) with a need for long-term replacement and risk of side effects. It cannot be excluded that pain killers (including opioids) and patients still at sleep may have given rise to inappropriately low levels of cortisol measured the 1st postsurgical day thereby contributing to false-positive results.

The proportion of patients with pituitary insufficiencies prior to surgery were in accordance with what has previously been reported with hypogonadotropic hypogonadism as the most common insufficiency, followed by central hypothyroidism and secondary AI (20, 24). In addition, a strong relationship between tumour size and numbers of insufficiencies was confirmed with a low risk of insufficiency by tumours $<20 \mathrm{~mm}$, and a high risk of insufficiency of all three axes by tumours $>40 \mathrm{~mm}(25$, 26). The GH axis is considered the most vulnerable axis, but evaluation of GH secretion was not possible since GH stimulation tests were not performed immediately pre- nor post-surgery.

In general, transsphenoidal surgery is considered a safe procedure with very low morbidity and mortality (5, 8). This was also the case in our cohort with no reported deaths within the first 30 postoperative days (data not shown). Furthermore, an overall beneficial effect on pituitary hormone secretion was found. The maximum number of post-surgery new insufficiencies per axis was $10 \%$ which is in accordance with previous papers reporting data on deterioration of pituitary function $(20,21,24,27)$. Analogous to other studies, we identified tumour size as a predictor of post-surgery insufficiency for the three investigated pituitary axis $(6,26,27)$. In our study, the adrenal axis had the highest recovery rate (24\%). In a meta-analysis from 2010 Murad et al. (5) found an overall pituitary function improvement of $30 \%(n=714)$ after pituitary surgery. However, since we report recovery rates and not only the improvement, the results are not fully comparable. In more recent studies, recovery rates of adrenal function similar to what we found have been reported $(24,27)$.

One of the strengths of the present study was the systematic follow-up at our department with regular Synacthen-tests and close observation of all patients. Another strength was the establishment of a normal range for plasma cortisol $30 \mathrm{~min}$ after ACTH stimulation in our laboratory, and that the majority of cortisol measurements in patients were done by the same method and laboratory facilities. An indisputable limitation of the study is that there were few cases of $\mathrm{AI}$ in the subgroup of patients who had earlybasalcortisolconcentrations measured. Therefore, the proposed cut-off for the initiation of hydrocortisone replacement should be taken with caution. Moreover, in a minority of patients, classification of adrenal function pre-surgery was not based on formal testing. Finally, it has been suggested that recovery of pituitary function may occur more than 6 months post-surgery, and, therefore, it cannot be excluded that more endocrine recoveries could have been observed with a longer follow-up (24).

In conclusion, the development of permanent $\mathrm{AI}$ after transsphenoidal surgery is a rare phenomenon, in our opinion not justifying routine prophylactic hydrocortisone treatment. Low 06:00 $\mathrm{h}$ plasma basal cortisol measured within $48 \mathrm{~h}$, increased tumour size and previous surgery were identified as possible risk factors for developing permanent AI post-surgery. Measurement of basal cortisol after pituitary surgery may predict overt AI, thereby securing vital glucocorticoid therapy and at the same time avoiding unnecessary glucocorticoid treatment in patients with an intact adrenal axis. A basal post-surgery plasma cortisol cut-off around $300 \mathrm{nmol} / \mathrm{L}$ was suggested but will eventually depend on the actual method for cortisol measurement (19), and the result needs confirmation from additional prospective studies. Finally, our study shows that transsphenoidal surgery had an overall beneficial effect on pituitary function.

\section{Declaration of interest}

The authors declare that there is no conflict of interest that could be perceived as prejudicing the impartiality of the research reported.

\section{Funding}

U F R's research salary was supported by a grant from The Kirsten and Freddy Johansen's Fund.

\section{Data sharing and data accessibility}

The data that support the findings of this study are available from the corresponding author upon reasonable request.

\section{References}

1 Ostrom QT, Patil N, Cioffi G, Waite K, Kruchko C \& Barnholtz-Sloan JS. CBTRUS statistical report: primary brain and other central nervous system tumors diagnosed in the United States in 2013-2017. NeuroOncology 202022 (Supplement 2) iv1-iv96. (https://doi.org/10.1093/ neuonc/noaa200)

2 Fernández-Balsells MM, Murad MH, Barwise A, Gallegos-Orozco JF, Paul A, Lane MA, Lampropulos JF, Natividad I, Perestelo-Pérez L, De León-Lovatón PGP, et al. Natural history of nonfunctioning pituitary adenomas and incidentalomas: a systematic review and metaanalysis. Journal of Clinical Endocrinology and Metabolism 201196 905-912. (https://doi.org/10.1210/jc.2010-1054) 
3 Prete A, Corsello SM \& Salvatori R. Current best practice in the management of patients after pituitary surgery. Therapeutic Advances in Endocrinology and Metabolism 2017 833-48. (https://doi. org/10.1177/2042018816687240)

4 Stack BC, Bimston DN, Bodenner DL, Brett EM, Dralle H, Orloff LA, Pallota J, Snyder SK, Wong RJ \& Randolph GW. American Association of Clinical Endocrinologists and American College of Endocrinology disease state clinical review: postoperative hypoparathyroidism definitions and management. Endocrine Practice 201521 674-685. (https://doi.org/10.4158/EP14462.DSC)

5 Murad MH, Fernández-Balsells MM, Barwise A, Gallegos-Orozco JF, Paul A, Lane MA, Lampropulos JF, Natividad I, Perestelo-Pérez L, De León-Lovatón PGP, et al. Outcomes of surgical treatment for nonfunctioning pituitary adenomas: a systematic review and meta-analysis. Clinical Endocrinology 201073 777-791. (https://doi. org/10.1111/j.1365-2265.2010.03875.x)

6 Zhang R, Wang Z, Gao L, Guo X, Feng C, Deng K, Lian W, Yao Y, Feng M, Bao X, et al. Clinical characteristics and postoperative recovery of hypopituitarism in patients with nonfunctional pituitary adenoma. World Neurosurgery 2019126 e1183-e1189. (https://doi. org/10.1016/j.wneu.2019.03.062)

7 Lake MG, Krook LS \& Cruz SV. Pituitary adenomas: an overview. American Family Physician 201388 319-327.

8 Karki M, Sun J, Yadav CP \& Zhao B. Large and giant pituitary adenoma resection by microscopic trans-sphenoidal surgery: surgical outcomes and complications in 123 consecutive patients. Journal of Clinical Neuroscience 201744 310-314. (https://doi.org/10.1016/j. jocn.2017.07.015)

9 Esposito D, Olsson DS, Ragnarsson O, Buchfelder M, Skoglund T \& Johannsson G. Non-functioning pituitary adenomas: indications for pituitary surgery and post-surgical management. Pituitary 201922 422-434. (https://doi.org/10.1007/s11102-019-00960-0)

10 Klose M, Lange M, Kosteljanetz M, Poulsgaard L \& Feldt-Rasmussen U. Adrenocortical insufficiency after pituitary surgery: an audit of the reliability of the conventional short synacthen test. Clinical Endocrinology 200563 499-505. (https://doi.org/10.1111/j.13652265.2005.02368.x)

11 Fleseriu M, Hashim IA, Karavitaki N, Melmed S, Murad MH, Salvatori R $\&$ Samuels MH. Hormonal replacement in hypopituitarism in adults: an endocrine society clinical practice guideline. Journal of Clinical Endocrinology and Metabolism 2016101 3888-3921. (https://doi. org/10.1210/jc.2016-2118)

12 Hána V, Ježková J, Kosák M, Kršek M, Marek J, Netuka D, Hill M \& Hána V. Prediction of adrenocortical insufficiency after pituitary adenoma surgery using postoperative basal cortisol levels. Physiological Research 201564 531-536. (https://doi.org/10.33549/ physiolres.932875)

13 Karaca Z, Tanriverdi F, Atmaca H, Gokce C, Elbuken G, Selcuklu A, Unluhizarci K \& Kelestimur F. Can basal cortisol measurement be an alternative to the insulin tolerance test in the assessment of the hypothalamic-pituitary-adrenal axis before and after pituitary surgery? European Journal of Endocrinology 2010163 377-382. (https:// doi.org/10.1530/EJE-10-0229)

14 Jayasena CN, Gadhvi KA, Gohel B, Martin NM, Mendoza N, Meeran K \& Dhillo WS. Day 5 morning serum cortisol predicts hypothalamicpituitary-adrenal function after transsphenoidal surgery for pituitary tumors. Clinical Chemistry 200955 972-977. (https://doi.org/10.1373/ clinchem.2008.117374)

15 Prencipe N, Parasiliti-Caprino M, Gatti F, Penner F, Berton AM, Bona C, Caputo M, D’Angelo V, Cappiello V, Gasco V, et al. Second day morning cortisol levels after transsphenoidal surgery are accurate predictors of secondary adrenal insufficiency with diagnostic cut-offs similar to non-stressed conditions. Neuroendocrinology 2021111 639-649. (https://doi.org/10.1159/000509092)

16 Inder WJ \& Hunt PJ. Glucocorticoid replacement in pituitary surgery: guidelines for perioperative assessment and management. Journal of Clinical Endocrinology and Metabolism 200287 2745-2750. (https://doi. org/10.1210/jcem.87.6.8547)

17 Courtney CH, McAllister AS, McCance DR, Bell PM, Hadden DR, Leslie H, Sheridan B \& Atkinson AB. Comparison of one week 0900 h serum cortisol, low and standard dose synacthen tests with a 4 to 6 week insulin hypoglycaemia test after pituitary surgery in assessing HPA axis. Clinical Endocrinology 200053 431-436. (https://doi. org/10.1046/j.1365-2265.2000.01106.x)

18 de Vries F, Lobatto DJ, Bakker LEH, van Furth WR, Biermasz NR \& Pereira AM. Early postoperative HPA-axis testing after pituitary tumor surgery: reliability and safety of basal cortisol and CRH test. Endocrine 202067 161-171. (https://doi.org/10.1007/s12020-019-02094-6)

19 Klose M, Hilsted L \& Feldt-Rasmussen U. Method-specific serum cortisol responses to the ACTH test: comparison of two generations of Roche automated immunoassays using polyclonal vs MBAs. Endocrine Abstracts 201641 EP22. (https://doi.org/10.1530/endoabs.41.EP22)

20 Gerges MM, Rumalla K, Godil SS, Younus I, Elshamy W, Dobri GA, Kacker A, Tabaee A, Anand VK \& Schwartz TH. Long-term outcomes after endoscopic endonasal surgery for nonfunctioning pituitary macroadenomas. Journal of Neurological Surgery 2021134 535-546. (https://doi.org/10.3171/2019.11.JNS192457)

21 Chang EF, Sughrue ME, Zada G, Wilson CB, Blevins LS \& Kunwar S. Long term outcome following repeat transsphenoidal surgery for recurrent endocrine-inactive pituitary adenomas. Pituitary 201013 223-229. (https://doi.org/10.1007/s11102-010-0221-z)

22 Broersen LHA, Pereira AM, Jørgensen JOL \& Dekkers OM. Adrenal insufficiency in corticosteroids use: systematic review and metaanalysis. Journal of Clinical Endocrinology and Metabolism 2015100 2171-2180. (https://doi.org/10.1210/jc.2015-1218)

23 Joseph RM, Hunter AL, Ray DW \& Dixon WG. Systemic glucocorticoid therapy and adrenal insufficiency in adults: a systematic review. Seminars in Arthritis and Rheumatism 201646 133-141 (https://doi. org/10.1016/j.semarthrit.2016.03.001)

24 Harary M, DiRisio AC, Dawood HY, Kim J, Lamba N, Cho CH, Smith TR, Zaidi HA \& Laws ER. Endocrine function and gland volume after endoscopic transsphenoidal surgery for nonfunctional pituitary macroadenomas. Journal of Neurological Surgery 2019131 1142-1151. (https://doi.org/10.3171/2018.5.JNS181054)

25 Nomikos P, Ladar C, Fahlbusch R \& Buchfelder M. Erratum: Impact of primary surgery on pituitary function in patients with nonfunctioning pituitary adenomas - a study on 721 patients. Acta Neurochirurgica 2004146 433. (https://doi.org/10.1007/s00701-0040247-y)

26 Cerina V, Kruljac I, Radosevic JM, Kirigin LS, Stipic D, Pecina HI \& Vrkljan M. Diagnostic accuracy of perioperative measurement of basal anterior pituitary and target gland hormones in predicting adrenal insufficiency after pituitary surgery. Medicine 201695 e2898. (https:// doi.org/10.1097/MD.0000000000002898)

27 Little AS, Gardner PA, Fernandez-Miranda JC, Chicoine MR, Barkhoudarian G, Prevedello DM, Yuen KCJ \& Kelly DF. Pituitary gland recovery following fully endoscopic transsphenoidal surgery for nonfunctioning pituitary adenoma: results of a prospective multicenter study. Journal of Neurological Surgery 2020133 1732-1738. (https://doi.org/10.3171/2019.8.JNS191012)

Received in final form 27 May 2021

Accepted 16 June 2021

Accepted Manuscript published online 17 June 2021 https://ec.bioscientifica.com https://doi.org/10.1530/EC-21-0155 (c) 2021 The authors Published by Bioscientifica Ltd

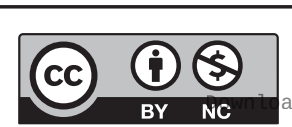

This work is licensed under a Creative Commons Attribution-NonCommercial 4.0 International License. ded from Bioscientifica.com at 04/26/2023 02:00:27PM 